\title{
Global health and global bioethics
}

Saúde global e bioética global

Salud global y bioética global

Henk ten Have ${ }^{1}$

\begin{abstract}
Covid-19 is not merely a national or regional threat but a global one. It requires coordinated action of the global community. Such action, as argued in this paper, should primarily focus on the question how to prevent the next pandemic. Humankind has been warned multiple time for emerging diseases and the risks of pandemics, although no preparatory responses have been undertaken. Preventive interventions are possible since it is known how and where infectious diseases emerge. Such interventions proceed on the basis of shared vulnerability and responsibility for global health. The fact that they have been inadequate thus far, can be considered as a serious moral failure.
\end{abstract}

\section{Keywords}

Covid-19. Global health. Global bioethics. Vulnerability.

\section{Resumo}

Covid-19 não é apenas uma ameaça nacional ou regional, mas global. Requer uma ação coordenada da comunidade global. Tal ação, conforme argumentado neste artigo, deve concentrar-se principalmente na questão de como prevenir a próxima pandemia. A humanidade foi advertida várias vezes sobre doenças emergentes e os riscos de pandemias, embora nenhuma resposta preparatória tenha sido realizada. As intervenções preventivas são possíveis desde que seja sabido como e onde surgem as doenças infeciosas. Tais intervenções procedem com base na vulnerabilidade e responsabilidade compartilhadas pela saúde global. O facto das intervenções terem sido inadequadas até ao momento pode ser considerado uma falha moral grave.

\section{Palavras-chave}

Covid-19. Saúde global. Bioética global. Vulnerabilidade.

\section{Resumen}

Covid-19 no es simplemente una amenaza nacional o regional, sino global. Requiere una acción coordinada de la comunidad global. Tal acción, como se argumenta en este documento, debe enfocarse principalmente en la pregunta de cómo prevenir la próxima pandemia. La humanidad ha sido advertida varias veces sobre enfermedades emergentes y los riesgos de pandemias, aunque no se han tomado respuestas preparatorias. Las intervenciones preventivas son posibles ya que se sabe cómo y dónde surgen las enfermedades infecciosas. Estas intervenciones se basan en la vulnerabilidad y la responsabilidad compartidas por la salud mundial. El hecho de que hayan sido inadecuadas hasta el momento puede considerarse como un grave fallo moral.

\section{Palabras clave}

Covid-19. Salud global. Bioética global. Vulnerabilidad.

\footnotetext{
${ }^{1}$ Professor emeritus, Center for Healthcare Ethics, Duquesne University, Pittsburgh, United States; Research Professor, Anahuac University, Huixquilucan, Mexico. https://orcid.org/0000-0002-3224-7943. E-mail: tenhaveh@duq.edu
} 


\section{Introduction}

The Covid-19 pandemic is a global phenomenon in at least three dimensions: it affects people everywhere across the world, not respecting any borders; it demands a common response since the world will not be secure as long as the virus is disseminating in some corners of the globe; and it is provoked and spread through processes of globalization. These characteristics explain why the pandemic is not a national or regional threat but a global health challenge. International cooperation and solidarity are required to cope with such threat. Since global health is related to the social and environmental conditions in which people live, coping efforts should not merely be directed at curative interventions and care arrangements, but also on preparedness and prevention. It is a moral failure that the world community has not taken significant steps to prevent the emergence of the pandemic. Now that societies are shaken by Covid-19, many want to return to normal conditions as soon as possible. However, when the current threat is over, humankind need to prepare for future pandemics, and take global action to prevent further viral menaces.

\section{The global context of health}

Infectious diseases are for some time high on the list of threats to global health. In the 1990s, the notion of emerging infectious diseases signaled that pandemics can be expected but not predicted, and that preparedness and preventive efforts are crucial for the immediate future. This notion itself materialized in the context of modified thinking about the concept of health. Based on the ideas of miasmatism and hygiene, sanitary reforms have been undertaken in many countries. In the $19^{\text {th }}$ century, European countries started to cooperate in the domain of healthcare, confronted with recurrent epidemics of cholera and the need to control the spread of infections. For the first time, international sanitary conferences were convened where delegates deliberated about the best ways to counter infectious diseases.

(1) Such efforts were certainly not disinterested since many European countries had extensive colonial empires and were afraid that so-called 'tropical diseases' could be imported; they were furthermore concerned about possible disruption in trade and commerce. In the early $20^{\text {th }}$ century, several international institutions are established for data collection, epidemiological studies, and policy implementation, culminating in the creation of the World Health Organization in 1946. While in the past pandemics have been approached from a limited, and often Eurocentric perspective, the international dimensions of health and disease (and thus the pan in the term pandemics) are now taken seriously, evidenced in changing 
terminology. 'International health' involves cooperation between a limited number of countries and only a few disciplines with the assumption that the expertise and provision of aid is the prerogative of some developed countries whereas the primary concern is with diseases of the developing world. The term 'world health' indicates a broader specter: health does not merely play a role in the relations between separate countries but is a concern for people everywhere, thus transcending national boundaries. It also recognizes that health is significantly determined by social and environmental conditions beyond borders. To address health demands therefore global cooperation with the assistance of a broad range of disciplines, not only healthcare, epidemiology, and virology but also statistic modelling, social sciences, management and policy science, economics, and political sciences. This broader perspective, as well as the awareness that many health challenges are related to processes of globalization that expose considerable health inequalities among and within countries is nowadays summarized as 'global health.' (2) The term is increasingly used since $2000 .^{2}$ (3)

\section{Global health}

The notion of global health basically affirms that health is a common concern for humankind. Its focus is on the health of global citizens, i.e., people everywhere on the globe. Health issues are not limited within national borders since our health cannot be separated from the health of everyone else. This is evident when a pandemic disease strikes; it will affect people regardless of where they are located. This focus implies that collective action and cooperation is required, involving many actors and disciplines. Another implication is the recognition that human beings share not only similar vulnerabilities but also the capacity to address challenges, for example with the potential of knowledge and technology. Finally, it implies that health is not the same everywhere. Health threats and hazards can affect some populations more severely than others while determinants of health (such as poverty) have more negative impacts in some places rather than other. Nonetheless, since health is interconnected in the global world, localized threats can easily become global. Contemporary economic globalization leads to inequitable distribution of benefits and risks, and monitoring global health is a way to minimize inequities through global health policies. Therefore, health disparities are a concern for all health policy makers, wherever they occur. The significance of these characteristics of global health is that it requires global governance. (4) However,

\footnotetext{
${ }^{2}$ A PubMed search with the keyword global health shows 564 publications in 1990, 2,071 in 2000, and 45,624 in 2020.
} 
the perpetual challenge, as illustrated in the policy responses to the Covid-19 pandemic, is that the implementation of a common framework for ameliorating and preventing of disease is often hampered by efforts to protect national security and trade. (5)

Although the term global health has different interpretation and definitions, its scope is broader than public health with which it shares many characteristics. It differs from public health in its geographical reach (public health is focused on countries, communities and even cities), its level of cooperation (public health usually does not require global cooperation), and objectives (public health mainly focuses on prevention activities for populations). ${ }^{3}$ (6) Anyway, the notion of global health introduces a new perspective in two ways: it draws attention to the interactions between health and the environment, and it highlights the importance of a broader global ethics framework for health interventions. The first point is emphasized in the interconnectedness of health. Not only is the health of all human beings linked so that a disease somewhere has implications, and often risks for people anywhere, but human health is also linked to social conditions, so that for example poverty and structural health inequalities should be eradicated in the world since they are associated with increased morbidity and mortality and can threaten the gains in health in richer countries. More recent is the awareness that health is dependent on environmental circumstances. Degradation of the environment and loss of biodiversity jeopardize human health but also the provision of safe water, clean air, and adequate nutrition. The idea that the environment is a crucial determinant of health, not only for individual persons but for the entire population of the planet, is nowadays expressed in the wider concept of 'planetary health'4 underlining that human health cannot be separated from the health of the earth. $(7,8)$ On this basis it is argued that policies and governance should not be concerned with an abstract image of the globe but with the predicament of the new era of the Anthropocene in which humans are rapidly deteriorating the conditions under which they exist, endangering health and civilization, not in the distant future but in the realities of today. The removal of disease and the improvement of health as the larger purpose of healthcare are impossible without preserving biodiversity, and reducing environmental and socio-economic hazards. In sum, health should be considered from an ecological point of view, besides a medical and social one. The second element is that the perspective of global health advocates a broader approach to ethics. The

\footnotetext{
${ }^{3}$ For example, Koplan et al. (6) define global health as "an area for study, research and practice that places a priority on improving health and achieving equity in health for all people worldwide."

${ }^{4}$ Planetary health is defined as "the health of human civilisation and the state of the natural systems on which it depends." (7)
} 
interconnections between medical, social and environmental concerns have generated global bioethics as an ethical framework that takes these concerns into account, and works with a larger set of moral viewpoints such as vulnerability, solidarity, cooperation, social responsibility, equality, diversity, and future generations.

\section{The ecological perspective}

The consequence of interconnectivity is global vulnerability. Processes of globalization have resulted in a world that not only creates more and new threats, but they have also undermined the traditional protection mechanisms (social security and welfare systems, family support systems), eroding the abilities of individuals and communities to cope with threats. Entire categories of people are disenfranchised, powerless and voiceless. The fact that the world has become increasingly interconnected and interdependent has created a sense of mutual vulnerability. In the words of the Director-General of the World Health Organization: "Vulnerability is universal." (9) Being vulnerable is often the result of a range of social, economic and political conditions, and therefore beyond the power and control of individuals. Because it is related to globalization, vulnerability can no longer be framed, as it usually is in mainstream bioethics, as an individual affair. The background of this common framing is the ethical principle of respect for autonomy. Fragility or weakness reduce or impair the capacity of persons to make autonomous decisions (for example, the capability to give informed consent) so that they no longer have the ability to protect their own interests. Such vulnerable individuals need special protection. From the perspective of global bioethics, however, vulnerability may be caused by structural social, economic and political determinants that disadvantage people; they are made vulnerable in specific contexts and situations, so that vulnerability is first of all related to the ethical principles of justice, solidarity and equality, rather than individual autonomy. Vulnerability is then the fall-out of processes of globalization that have made everyday existence more precarious, exposing it to more hazards and threats, and decreasing the capacities to cope. In this perspective, relating vulnerability to autonomy diverts attention away from the circumstances that make subjects vulnerable.

Vulnerability as a global phenomenon has significant implications for the bioethical debate. The first is the recognition that humans are social beings. The common idea that individual persons are autonomous and in control is challenged. Since the human condition is inherently fragile, all human beings are sharing the same predicament. Because our bodily 
existence is vulnerable, and embedded in environments such as the virosphere, humans have developed institutions and social arrangements to protect themselves. Vulnerability is neither an individual accomplishment nor a threat; it signifies that we are open to the world; that we can engage in relationships with other persons; that we can interact with the world. It is not a deficit but a positive phenomenon; it is the basis for exchange and reciprocity between human beings. We cannot come into being, flourish and survive if our existence is not connected to the existence of others. The notion of vulnerability therefore refers to solidarity and mutuality, the needs of groups and communities, not just those of individuals. The second implication is that vulnerability mobilises a different response: if vulnerability is a symptom of the growing precariousness of human existence and is exacerbated in certain conditions, the social and environmental context can no longer be ignored in bioethical analysis. On the contrary, bioethics should focus on the distribution and allocation of vulnerability at global level. Instead of focusing on individual deficits, analysis should criticise the external determinants that expose individuals to possible damage and harm. It also means that individual responses are insufficient; what is needed is a collective response, in other words social and political action. $(10,11)$

\section{Emerging diseases}

The perception of global vulnerability has motivated the idea that infectious diseases are emerging and re-emerging. This idea became more widely disseminated around the same time as the notion of global health. Since the 1992 report of the Institute of Medicine in the United States, emerging diseases became a fashionable topic of research and policy. ${ }^{5}$ The report articulates three assumptions that are reiterated numerous times since its appearance. One is that new microbial diseases will emerge, although it cannot be predicted when and where. Another assumption is that environmental changes account for most emerging diseases. ${ }^{6}$ These changes are anthropogenic, i.e., caused by human behaviour. ${ }^{7}$ Infectious diseases are not just the effect of a specific pathogen but they have environmental and social causes; diseases emerge because the environments of pathogens have been transformed. A third assumption is that a paradigm shift is necessary from response to

\footnotetext{
${ }^{5}$ In 1995 the journal Emerging Infectious Diseases was launched. A PubMed search with the keyword 'emerging diseases' shows 1,651 publications in 1992, and 40,356 in 2020.

6 "Although it is impossible to predict their individual emergence in time and place, we can be confident that new microbial diseases will emerge." (12, p.23).

7 "In fact, environmental changes probably account for most emerging diseases." (12, p.42).
} 
prevention. Experiences with previous pandemics have learned that vigilance is lessening once the disease threat is over, but a continuous effort will be needed. The discourse of emerging diseases therefore has negative and positive implications. First of all, it is a warning against human exploitation of surrounding nature. It also cautions against overconfidence in the accomplishments of post-war medicine which has made effective medication as well as vaccines available for major infectious diseases. Secondly, the increasing awareness that humans, animals, and biodiversity are connected, makes positive action possible. We know that most infectious diseases emerge from animals, so that a broader concept of One Health should be applied, requiring the collaboration of human, animal and ecological health professionals, which is especially important for prevention of zoonotic diseases. Most emerging diseases are transmitted to humans through contact with animals. ${ }^{8}$ (13) Pathogens emerge from their natural environment in the wild (primates, bats, and rodents). Domestic animals bridge the gap between humans and wild animals. The source of Covid-19 is still uncertain but presumable it emerged from wildlife, as has been the case with the SARS pandemic. Another insight is that infectious diseases are associated with global civilization: urbanization, deforestation, fast and easy transportation, consumption of wild game, and industrial livestock practices, while rising temperatures will increase their incidence across the world. $(13$, p. 161; 14) Furthermore, we know that diseases emerge in certain hotpots, so that global surveillance can detect them in an early stage. Last but not least, prevention at the macro-level is possible for most epidemic and pandemic diseases. It is a mistake to assume that pandemics are not predictable or preventable, and that they occur randomly. (13, p. 242) This will be a challenge since micro-organisms are everywhere, and unavoidably connected with life on the planet. New pathogens will continuously emerge, and existing pathogens will mutate and adapt to their environment. But disease outbreaks are not just natural events but symptoms of a weak and less vigilant public health system. ${ }^{9}$

\section{Preparedness and prevention}

Multiple times a "coming storm" has been predicted, particularly with a microbe combining high lethality and transmissibility. $(13, \mathrm{p} .16)$ Confronted with a current pandemic such as Covid-19, it should not be taken for granted that this will be the expected disaster. SARS-CoV-2 is not a very deadly virus compared to other potential viruses but it is disastrous

\footnotetext{
${ }^{8}$ Pandemics “... almost always begin with the transmission of an animal microbe to a human..." (13, p.3).

${ }^{9}$ We are confronted with an "endless dance between microbes and humans." (15, p. 255).
} 
because it overwhelms the healthcare system and prolongs its impact because public health is insufficient. The Covid pandemic could be a "rehearsal for a potentially more lethal pandemic." (15, ix) In light of these predictions, two responses are promoted: preparedness and prevention.

\section{Preparedness}

The idea to be ready for potential public health emergencies in the immediate future became influential after the anthrax mailings following the 9/11 terror attacks in the United States in 2001. (16) ${ }^{10}$ Evidently, dangerous micro-organisms could be used to threaten populations and the best way for societies to protect themselves is to apply a range of monitoring and detection activities but also prepare themselves for the event and be ready with countermeasures so that they have an adequate capability to respond. The concept of preparedness is also applied to unintentional threats with the result that emerging diseases are framed as a security concern, in keeping with the military vocabulary that has always been used to characterize infections as invasions. The context of biosecurity emphasizes that infectious diseases endanger societies, economic exchange and political stability, reinforcing the role of states. The frame of biosecurity introduces a specific perspective with characteristics that are recognizable today in responses to Covid-19. First, it assumes a polarity: threats are foreign, coming from the outside, and they must be contained and controlled in order to keep citizens safe. One of the consequences is that antagonism rather than global relationship is promoted, minimizing the moral vocabulary of global solidarity. Second, securitization distorts priorities. Because it focuses on specific pathogens and the areas where they emerge, the conditions in which they are produced are not addressed. Concerns of inequality, injustice and poverty that often contribute to the spread of diseases cannot be discussed while the attention primarily goes to micro-organisms whereas free trade and biodiversity loss are not considered as security problems. Third, the frame of biosecurity regards assessment of risks as a technical issue. Evaluating risks is regarded as the prerogative of experts, not as the outcome of public debate about which risks are acceptable and to whom. It is argued that the common good should be protected but there is little space for dialogue, engaging communities, and transparency. Framing health and disease as security issues has prompted governments to introduce legislation and practices that restrict

\footnotetext{
10 The history of bio-preparedness goes back to the beginning of the Cold War in the late 1940s and 1950s.
} 
human rights, surveil the public sphere, and practically eliminate privacy. Finally, biosecurity requests a specific approach to biological threats. Since the future is filled with imminent catastrophes and the emergence of these threats is unpredictable, the best strategy is to take preemptive action before the actual threat occurs. That means stockpiling drugs, vaccines, and protective materials. During the 2009 swine flu outbreak for example, Western governments invested hundreds of millions of dollars to stockpile and distribute the antiviral drug Tamiflu, to little avail since the outbreak was much milder than predicted. The resources were not invested to improve the public health infrastructure in most countries, neither in providing clean drinking water, food or basic healthcare in developing countries to make them more resilient in case of diseases. (4, p.93)

After the SARS epidemic in 2002-2003, the World Health Organization issues a plan to prevent similar outbreaks in the future. It recommends better preparation to respond effectively, and to make supplies of personal protective equipment and essential medicines. (17) Two years later, an evaluation of the responses to SARS concludes that humankind has been lucky this time since the SARS-CoV virus could be relatively easily contained since there was no asymptomatic transmission, so that the traditional public health measures of isolation, quarantine and contact tracing could control the dissemination of the virus. However, these measures were not perfect in some countries and it was unclear why the outbreak stopped. (18) Looking back at the Ebola Virus Disease outbreak (2013-2016), independent assessment panels conclude that the World Health Organization as the leading global health agency has insufficient capacity to respond to a public health emergency. Countries do not have the capacity to detect, report, and respond rapidly, while a robust global system to protect all people based on solidarity, shared vulnerability and responsibility is missing. Many recommendations are made to better prepare for future outbreaks. $(19,20)$

Following the avian flu outbreaks in 2003 and $2004\left(\mathrm{H}_{5} \mathrm{~N}_{1}\right.$ influenza virus) affecting mainly birds and occasionally humans, and alerted by the SARS outbreak, the World Health Organization, updating its Influenza Pandemic Plan of 1999, launches the Global Influenza Preparedness Plan, urging countries to make national bio-preparedness plans. Each country is expected to achieve international harmonization of preparedness measures. ${ }^{11}$ (21) Many countries make these plans in view of a deadly pandemic that experts warn will surely come. Over the years, drills and exercises with simulated pandemics are hold. For example, in 2012

\footnotetext{
11 "Every country is strongly urged to develop or update a national influenza preparedness plan..." (21)
} 
the Robert Koch Institute in Germany tests a hypothetical scenario with a new virus, transferable from person to person, and with a mortality rate of $10 \%$. Many of the effects of the current Covid pandemic on healthcare, society and the economy are predicted. The results are incorporated in a National Pandemic Plan. (22) In 2015, a report in the United States warns that the majority of states are not adequately capable to prevent, detect, diagnose and respond to infectious disease outbreaks. It urgently recommends to expand resources for public health infrastructure. (23) In 2016, the government of the United Kingdom organizes Exercise Cygnus to test the country's readiness for a pandemic with a scenario of a devastating influenza pandemic, affecting almost half of the population. The conclusion is that preparedness and response are insufficient to cope with a severe pandemic. The report however is never published. $(24,25$, p.25) A few years later, just before the Covid-19 pandemic, a similar simulation exercise takes place in the United States. This so-called Crimson Contagion shows that the federal government and the states are incapable to effectively respond to a severe influenza pandemic; funding and coordination are lacking, and production capacity for protective equipment, face masks, and ventilators is insufficient. The report is only published in September 2020. (26)

Although preparedness is advocated since a long time, plans have been developed, and exercises have taken place, the Covid-19 pandemic demonstrates that countries were not prepared. One reason might be that for a long time the focus was on biosecurity in a limited sense, fixated on the threat of bioterrorism. Another reason is that serious pandemics would not be reasonably expected. In the meantime, the world has seen epidemics of Ebola and Zika but they primarily affected a limited region and did not transform into global pandemics. The focus of preparedness efforts was also primarily directed at influenza, because the most recent deadly pandemic has been the Spanish flu. Anxieties concerning avian flu ( $\mathrm{H}_{5} \mathrm{~N}_{1}$ virus) since 2003 did not materialize since a pandemic has not occurred. Swine flu, caused by a similar virus as the Spanish flu $\left(\mathrm{H}_{1} \mathrm{~N}_{1}\right)$, developed into a pandemic in 2009 but it turned out to be milder than seasonal flu. The alarmist framing of the threat, and the gap between what was expected and what occurred might have relaxed preparedness efforts and produced "preparedness fatigue." (27, p.172) As soon as a threat is not manifest or diminishes, priorities change with the result that resources for preparedness are not consistently allocated. Especially in Europe and North America there was "widespread complacency," with political leaders underestimating the danger. $(25$, p.35) Repeated warnings by national and international health organizations are ignored, and even the obvious 
evidence from simulation exercises showing lack of preparation has not instigated political action. This refers to a significant degree of contentment. The Global Health Security Index, first published in October 2019, concluded that no country is fully prepared for epidemics or pandemics. The countries that are best prepared are the United States, the United Kingdom, and the Netherlands. (28) Similar conclusions are advanced in a WHO study of national and regional preparedness capacities in 2018: more than 50\% of the 182 analyzed countries have the highest levels of operational readiness capacities. Most countries in the European region reported high levels of capacity to prevent, detect, and respond to a public health event. (29) Both studies are based on self-reported data, showing that especially high-income and middle-income countries are satisfied with their capacities to cope with a health emergency. Anyway, the Covid-19 pandemic simply overwhelmed all countries, developed or underdeveloped, and particularly affected high-income countries that assumed they are best prepared. Overestimation of own capacities was joined with underestimation of the risks and effects of the virus.

\section{Prevention}

In 1994, the Centers for Disease Control and Prevention in the United States proposed a prevention strategy for infectious diseases with four goals: surveillance and response; applied research; prevention and control; public health infrastructure. The strategy points out that research should not only be focused on virology and epidemiology but also on the role of behavioral factors that influence exposure to microbial threats. The importance of enhanced public communication of relevant information, as essential for the implementation strategies, is highlighted. Infrastructure requests attention for laboratory capabilities with surge capacity. But what is most important for prevention is monitoring and surveillance, not only nationally but globally: "Timely recognition of emerging infections requires early warning systems to detect such problems so they may be promptly investigated and controlled before they evolve into public health crises." (30) The science of pandemic prevention includes three steps: early identification of epidemics, assessment of the probability that they develop into pandemics, and stopping lethal pathogens before they become pandemic. (13, p. 207) Preventive approaches are feasible because it is known that microbes generally come from animals, and that some geographical areas pose greater risks that pathogens 'jump' to human because there is proximity between humans and animals. 
The emphasis on preventive activities is related to the growing importance of the ecological perspective mentioned above. Humankind is rapidly destroying biodiversity though it is essential for its health and survival. Global populations of mammals, birds, fish, amphibians and reptiles have dropped 68\% since 1970. Declining species populations are a measure of deteriorating overall ecosystem health. Deforestation, overexploitation, reduction of wildlife habitat, air and water pollution lead to continual destruction of nature, accelerated by climate change. (31) Loss of biodiversity and disruption of ecosystems create the conditions for the emergence of diseases. Animals that are reservoirs and hosts of viruses are driven from their natural environments, and come into closer contact with humans. The natural barriers between animals in which viruses are circulating and humans are disappearing. However, it is not nature itself that is threatening but human interference with natural ecosystems that creates human health risks. Because of the decline of tropical forest some regions in West Africa, the Amazon basin, and South-East Asia are known as emerging disease hotspots. The cycle of viral spillover will only be broken when human activity will change, and our relationship with nature transformed. (32) The same considerations apply to the Covid-19 pandemic. (33) Although its origins are still unclear, the virus has most probably crossed from bats into humans, with perhaps an intermediary host. Future pandemics will in all likelihood also be zoonotic diseases associated with environmental change and human behavior. Prevention of disease spillover, and thus future pandemics, is closely connected to efforts to mitigate the global challenge of climate change. The transformation towards green economies will be economically expensive but compared to the current costs of the Covid-19 catastrophe relatively moderate.

The ecological perspective affirms that the first action to avoid pandemics is to prevent further deterioration of biodiversity. Global surveillance is important but in fact too late. It is estimated that 1.7 million viruses exist in mammals and birds (where most pandemics originate) but less than $0.1 \%$ have been described. The majority of possible pathogens is not even discovered. (32) The challenge is enormous because most of the risks are unknown. The Institute of Medicine report in 1992 presents a long list of emerging infectious disease, with special attention to HIV, recognized in 1981. The WHO publishes in 2016 a blueprint for action to prevent epidemics, listing priority diseases with eleven pathogens for which few or no medical countermeasures are available (including two coronaviruses, SARS-CoV and MERS-CoV). (34) A later updated list includes Covid-19 but also 'Disease X.' This refers to a pathogen that is currently unknown but that can cause a serious epidemic in the near future. 
(35) It evokes the nightmare scenario of a virus that combines the characteristics of the influenza virus (highly transmissible) and SARS-CoV (high lethality). In 2016, the initiative is taken to establish the Global Virome Project, a ten-year research project with the aim to develop a viral database and to detect zoonotic viruses with pandemic potential. It recognizes that prevention and responses thus far have been inadequate. Arguing that global health requires global action, the project assumes the shared vulnerability of the world, and the need for cooperation and solidarity, as well as equitable access to research data and benefits. (36)

\section{Conclusion}

Pathogen surveillance is based on the image of war. Because emerging diseases cannot be eliminated, the enemies should be better understood so that they can be identified like terrorists before they do harm. We therefore need epidemic intelligence services, disease detectives, virus hunters, biodefense, and a "biological NATO" to defend the world against developing pathogens. (37) This military framework emphasizes a technical approach with data collection, anticipatory intervention and precise weaponry, assuming that war is inevitable, but it overlooks the possibilities for primary prevention. The significance of this framing is that it does not allow any space for considering shared moral responsibilities to prevent outbreaks. The notion of global health affirms that in many developing countries healthcare systems are fragile, and must be made more robust and resilient. Moreover, they do not have adequate surveillance capacity, and need support because if one country is vulnerable, all countries will be. Preparedness is a shared responsibility, and requires global solidarity. The failure to strengthen health infrastructure and to ameliorate shared vulnerabilities makes the fact that hardly any lessons are learned from previous pandemics a moral failure. It signifies that no attention is given to global justice, equality, vulnerability, and solidarity. The moral implications of the notion of global health are not taken seriously so that technical and militarized approaches will not produce satisfactory preparedness and prevention for the next pandemic. $(38,39)$

\section{References}

1. Howard-Jones N. The scientific background of the International Sanitary Conferences, 1851-1938. Geneva: World Health Organization; 1975. 
2. Brown TM, Cueto M, Fee E. The World Health Organization and the transition from "international" to "global" public health". American Journal of Public Health 2006; 96 (1): 6272.

3. Holst J. 2020. Global health - emergence, hegemonic trends and biomedical reductionism. Globalization and Health 2020; 16, 42. Available from:

https://doi.org/10.1186/s12992-020-00573-4

4. Ten Have $\mathrm{H}$. Wounded planet. How declining biodiversity endangers health and how bioethics can help. Baltimore: Johns Hopkins University Press; 2019.

5. Harrison M. A global perspective: Reframing the history of health, medicine, and disease. Bulletin of the History of Medicine. 2015;89:739-689.

6. Koplan JP, Bond TC, Merson MH, et al. 2009. Towards a common definition of global health. Lancet 2019; 373: 1993-1995.

7. Whitmee S, Haines A, Beyrer C, et al. Safeguarding human health in the Anthropocene epoch. Report of the Rockefeller Foundation-Lancet Commission on planetary health. Lancet 2015; 386: 1978.

8. Horton R, Beaglehole R, Bonita R, et al. From public to planetary health: a manifesto. The Lancet 2014; 383: 847.

9. WHO. World health report 2007 - A safer future: global public health security in the $21^{\text {st }}$ century. Geneva: WHO; 2007.

10. Ten Have $\mathrm{H}$. Vulnerability as the antidote to neoliberalism in bioethics. Revista Redbioetica/UNESCO 2014; 5 (1; no.9): 87-92.

11. Ten Have $H$. Respect for human vulnerability: The emergence of a new principle in bioethics. Journal of Bioethical Inquiry 2015; 12 (3): 395-408.

12. Institute of Medicine. Emerging infections. Microbial threats to health in the United States. Washington: National Academy Press; 1992.

13. Wolfe N. The viral storm. The dawn of a new pandemic age. New York: St. Martin's Griffin; 2011.

14. Wolfe ND, Panosian Dunavan C, Diamond J. Origins of major infectious diseases. Nature 2007; 447: 279-283.

15. Khan AS. The next pandemic. On the frontlines against humankind's gravest dangers. New York: PublicAffairs; 2020.

16. Fee E, Brown TM. Preemptive biopreparedness: Can we learn anything from history? American Journal of Public Health 2001; 91 (5): 721-726. 
17. World Health Organization. SARS risk assessment and preparedness framework. Geneva: WHO; 2004. Available from:

https://www.who.int/csr/resources/publications/CDS_CSR_ARO_2004_2.pdf

18. World Health Organization. Regional Office for the Western Pacific. SARS: How a global epidemic was stopped. Manila: WHO Regional Office for the Western Pacific; 2006. Available from: https://apps.who.int/iris/handle/10665/207501

19. World Health Organization. Report of the Ebola Interim Assessment Panel; 2015.

Available from: https://www.who.int/csr/resources/publications/ebola/report-bypanel.pdf?ua=1

20. Moon S, Sridhar D, Pate MA, et al. Will Ebola change the game? Ten essential reforms before the next pandemic. The report of the Harvard-LSHTM Independent Panel on the Global Response to Ebola. Lancet 2015; 386: 2204-2221.

21. World Health Organization. WHO global influenza preparedness plan: the role of WHO and recommendations for national measures before and during pandemics. Geneva: World Health Organization; 2005. Available from: https://apps.who.int/iris/handle/10665/68998

22. Ribes M. Covid-19 retrospective, a disaster that should have been averted. Bioethics Observatory, 2020, September 18. Available from:

https://bioethicsobservatory.org/2020/09/coronavirus-crisis-responsibilitiesexoneration/36839/

23. Trust for America's Health and Robert Wood Johnson Foundation. Outbreaks: protecting Americans from infectious diseases. Washington, 2015. Available from: https://www.tfah.org/report-details/outbreaks/

24. Pegg D. What was Exercise Cygnus and what did it find? The Guardian, 2020, May 7. Available from: https://www.theguardian.com/world/2020/may/07/what-was-exercisecygnus-and-what-did-it-find

25. Horton R. The Covid-19 catastrophe. Cambridge: Polity; 2020.

26. Department of Health and Human Services (HHS). Crimson Contagion 2019 Functional Exercise After-Action Report. Washington, 2020. Available from:

https://www.governmentattic.org/38docs/HHSaarCrimsonContAAR_2020.pdf

27. Brown J. Influenza. The hundred-year hunt to cure the deadliest disease in history. New York: Simon \& Schuster; 2018.

28. Global Health Security Index. Building collective action and accountability, 2019. Available from: https://www.ghsindex.org/wp-content/uploads/2019/10/2019-Global-HealthSecurity-Index.pdf

29. Kandel N, Chungong S, Omaar A, Xing J. Health security capacities in the context of Covid-19 outbreak: an analysis of International Health Regulations annual report data from 182 countries. Lancet 2020; 395: 1047-1053. 
30. Centers for Disease Control and Prevention. Addressing emerging infectious disease threats: a prevention strategy for the United States (Executive Summary). MMWR 43 (No. RR-5), 1994, 1-23.

31. World Wide Fund for Nature. Living Planet Report 2020 - Bending the curve of biodiversity loss. Gland (Switzerland): WWF; 2020. Available from:

https://f.hubspotusercontent20.net/hubfs/4783129/LPR/PDFs/ENGLISH-FULL.pdf

32. Daszak $P$. We are entering an era of pandemics - it will end only when we protect the rainforest. The Guardian, 2020, 28 July. Available from:

https://www.theguardian.com/commentisfree/2020/jul/28/pandemic-era-rainforestdeforestation-exploitation-wildlife-disease

33. Vidal J. 'Tip of the iceberg': is our destruction of nature responsible for Covid-19? The Guardian, 2020, March 18. Available from:

https://www.theguardian.com/environment/2020/mar/18/tip-of-the-iceberg-is-ourdestruction-of-nature-responsible-for-covid-19-aoe

34. World Health Organization. An R\&D Blueprint for action to prevent epidemics. Funding \& coordination models for preparedness and response, 2016. Available from:

https://www.who.int/blueprint/what/improving-

coordination/workstream_5_document_on_financing.pdf?ua=1

35. World Health Organization. Prioritizing diseases for research and development in emergency contexts, 2018. Available from: http://www.emro.who.int/pandemic-epidemicdiseases/news/list-of-blueprint-priority-diseases.html

36. Bellagio Initiative on the Global Virome Project. 2016. Available from:

https://static1.squarespace.com/static/581a4a856b8f5bc98311fb03/t/582120e4ff7c5080cc6 $11 \mathrm{fd} 6 / 1478566120350 / G V P+B e l l a g i o+I n i t i a t i v e . p d f$

37. Langreth R. Five steps to prevent the next pandemic. NDTV, 2021, Feb 4. Available from: https://www.ndtv.com/world-news/five-steps-to-prevent-the-next-pandemic-2362755

38. Smith MJ, Upshur REG. Ebola and learning lessons from moral failures: Who cares about ethics? Public Health Ethics 2015; 8 (3): 305-318.

39. Smith MJ, Upshur REG. Learning lessons from Covid-19 requires recognizing moral failures. Journal of Bioethical Inquiry 2020; 17: 563-566.

\section{Como citar este artigo}

Submetido em: 05/03/21

Aprovado em: 16/05/21

Ten Have H. Global health and global bioethics. Cadernos Ibero-Americanos de Direito Sanitário. 2021 jul./set.;10(3):5065. 